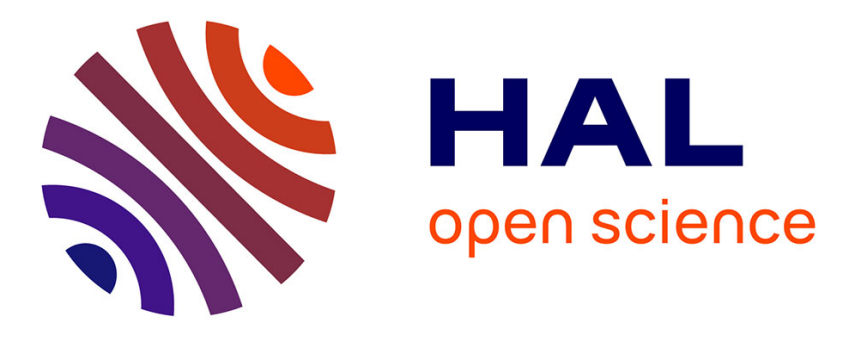

\title{
A Step Towards Customized Product Realization: Methodology for Sensing, Smart and Sustainable Enterprise
}

Dante Chavarría-Barrientos, Rafael Batres, Roberto Perez, Paul K. Wright, Arturo Molina

\section{To cite this version:}

Dante Chavarría-Barrientos, Rafael Batres, Roberto Perez, Paul K. Wright, Arturo Molina. A Step Towards Customized Product Realization: Methodology for Sensing, Smart and Sustainable Enterprise. 17th Working Conference on Virtual Enterprises (PRO-VE), Oct 2016, Porto, Portugal. pp.327-339, 10.1007/978-3-319-45390-3_28. hal-01614578

\author{
HAL Id: hal-01614578 \\ https://hal.inria.fr/hal-01614578
}

Submitted on 11 Oct 2017

HAL is a multi-disciplinary open access archive for the deposit and dissemination of scientific research documents, whether they are published or not. The documents may come from teaching and research institutions in France or abroad, or from public or private research centers.
L'archive ouverte pluridisciplinaire HAL, est destinée au dépôt et à la diffusion de documents scientifiques de niveau recherche, publiés ou non, émanant des établissements d'enseignement et de recherche français ou étrangers, des laboratoires publics ou privés.

\section{(c)(1)}

Distributed under a Creative Commons Attribution| 4.0 International License 


\title{
A Step Towards Customized Product Realization: Methodology for Sensing, Smart and Sustainable Enterprise
}

\author{
Dante Chavarria-Barrientos $^{1}$, Rafael Batres ${ }^{1}$, Roberto Perez ${ }^{1}$, Paul K. Wright ${ }^{2}$, \\ Arturo Molina ${ }^{1}$, \\ ${ }^{1}$ Tecnologico de Monterrey, Escuela de Ingeniería y Ciencias, Mexico \\ ${ }^{2}$ University of California, Berkeley, Berkeley, CA, United States \\ \{dante.chavarria, rafael.batres, roberto.perez.cu, armolina\}@itesm.mx \\ \{pwright\}@me.berkeley.edu
}

\begin{abstract}
New trends such as mass customization have appeared, where production volumes are flexible, customers require One of a Kind production, and product variety is large. To accomplish these demands, there is a necessity of flexible enterprise operations and reconfigurable manufacturing systems. Enterprise models, integration frameworks, collaborative systems and flexible/reconfigurable manufacturing systems allow facing such challenges. This paper presents a methodology aiming to support the design, creation and implementation of sustainable, smart and sensing manufacturing systems. $\mathrm{S}^{3}$ Enterprise (Sensing, Smart and Sustainable) Reference Model has been developed and used to create such systems. The $S^{3}$ Enterprise Reference Model uses a methodology based on action-research concept to pursue understanding and facilitating its implementation in Small and Medium Enterprises. The reference model is instantiated to define a Collaborative Networked Organization that is able to manufacture customized products. Finally, a case study is presented to demonstrate the usage and application of the methodology.
\end{abstract}

Keywords: Enterprise Modelling, Sustainable Manufacturing, Smart Organization, Sensing Enterprise, Collaborative Networks, Instantiation Methodology

\section{Introduction}

In mass customization, the manufacturing enterprises have to deliver low volume and customized products to satisfy the customer specific requirements. This is a complex task considering key characteristics of mass customization [1]. There are heterogeneous demand patterns due to dissimilar niches, low cost and high quality expectations, and short product life cycles. As a result, manufacturing systems need to be flexible and adaptive [1]. Conveniently, a list of enablers such as flexible manufacturing, Cyber Physical Systems, interactive computing technology, additive manufacturing can be used to generate such systems. However, such enablers need to be leveraged to be effective and implementable. One approach is through integration, collaboration and 
systematization. Integration among all levels of an enterprise support better decision making. Collaboration allows the union of multiple resources to fulfill a common end. Systematic design of manufacturing systems builds up know-how. Therefore, new developments include the learning from the previous designs.

Over the last three decades, the concept of manufacturing architectures has evolved to provide integration and systematization for the analysis and design of manufacturing enterprises. Early examples include the European ESPRIT project, ICAM architecture, ISO Manufacturing Automation Protocol, and GRAI architecture. Although they were an important step in the modeling of manufacturing companies, they were not aimed to implement different views. Then, a new set of architectures implemented the viewpoints concept: ARIS, CIM-OSA [2, 3], MOSES, Zachman's framework. The viewpoints allow focusing on particular aspects and therefore designing complex and large systems, such as enterprises [4].

Examples can be found in the literature regarding implementation of architectures. Monfared et al. [5] apply the CIM-OSA enterprise modelling approach to re-engineer the business process of an automotive industry. They create a reference model to develop new engine projects. Their study does not use the views as a central theme in the architecture. Nogueria et al. [6] proposes a new methodology based on actionresearch for the implementation of the business, system and technology models of the Zachman framework in Small and Medium Enterprises (SMEs). Because the case study was an IT enterprise, the methodology fall short in understanding the manufacturing implications. In the search of collaboration, Zwegers et al [7] presented an architectural framework called VERAM. It has the purpose to structure to support collaborative networks. The study identifies the need of a reference model to build particular models. Bernus [8] presented the use of Globemen reference model to create service virtual enterprises. An activity diagram showed the results, but the approach was not tested on a particular enterprise.

This paper proposes a methodology to define manufacturing enterprises. Such definition is achieved through an enterprise model. The concepts that support methodology are explained in section 2. The methodology is presented in section 3 . Special considerations must be considered when the methodology is followed to build a Collaborative Networked Organization (CNO) for personalized products; such implications are discussed in section 4. After that, to evaluate the methodology a case study is presented in section 5. Finally, section 6 provides conclusions.

\section{$2 \mathrm{~S}^{\mathbf{3}}$ Enterprise Reference Model + Action-Research}

The research is based on two concepts mainly. The first concept is the Sustainable, Smart and Sensing Enterprise Reference Model ( $\left.S^{3} E-R M\right)$ because it guides the analysis, design and implementation of an enterprise; and at the same time, it allows the adoption of the Sensing, Smart and Sustainable characteristics. These characteristics mean that the enterprise will be competitive in the digital economy [9]. The second concept is the action-research methodology to pursue understanding in a systematic way (which is a common characteristic in methodologies) and for its ability to implement frameworks in SMEs. The use of the $S^{3} E$ Reference Model and 
methodology will enable the design of Sensing, Smart and Sustainable Enterprises through the creation of partial and particular models. Fig. 1 illustrates this, where the $\mathrm{S}^{3} \mathrm{E}-\mathrm{RM}$ is used to create a partial model for Collaborative Networks that produce customized products; and subsequently the partial model is used to create the particular model for an enterprise of promotional articles. Both instantiations where achieved through action-research. Further explanation on how to make the instantiation appears in following sections.

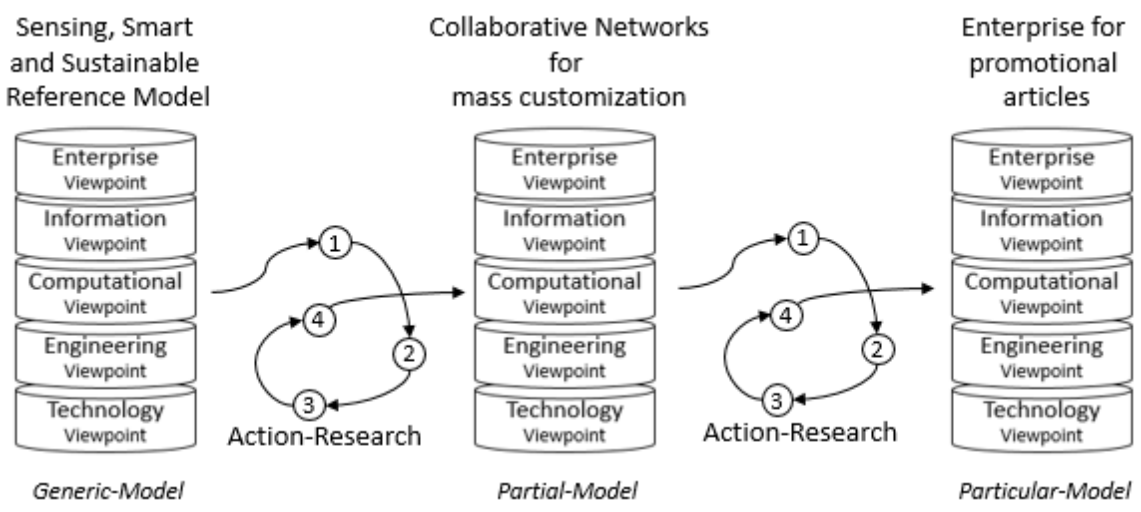

Fig. 1. Instantiation of the $S^{3}$ Enterprise (Sensing, Smart and Sustainable) reference model through action-research methodology.

\subsection{Sensing, Smart and Sustainable Enterprise - Reference Model}

The $S^{3} E-R M$ is the evolution of the Smart $x$ Sensing Enterprise Reference Model $\left(S^{2} E-\right.$ $R M)$ presented in [10]. The $S^{2} E-R M$ is an enterprise reference model that supports the concepts of smart and sensing. The $S^{2} E-R M$ has been used to design and create manufacturing collaborative networks [10]. $S^{3} E-R M$ is an evolution of $S^{2} E-R M$ in which sustainability is considered. Sustainable manufacturing refers to a manufacturing execution where sustainability is guaranteed on its three pillars i.e. environmental, social and economic. The reference model aims at achieving three main tasks:

- Identify enterprise requirements that support the concepts of Sensing, Smart and Sustainable.

- Guide the analysis, design, planning and implementation of the enterprise system.

- Organize the process of implementation (people, methods and tools) to evolve the Sensing, Smart and Sustainable System towards the desired level of automation.

The $S^{3} E-R M$ enlist five viewpoints (e.g. enterprise, information, computation, engineering and technology) based on the ISO/IEC 19439 ODP-RM standard [11]. The $S^{3} E-R M$ has a list of tools and activities to define the each viewpoint (See Fig. 2). Further explanation is provided in [10]. 


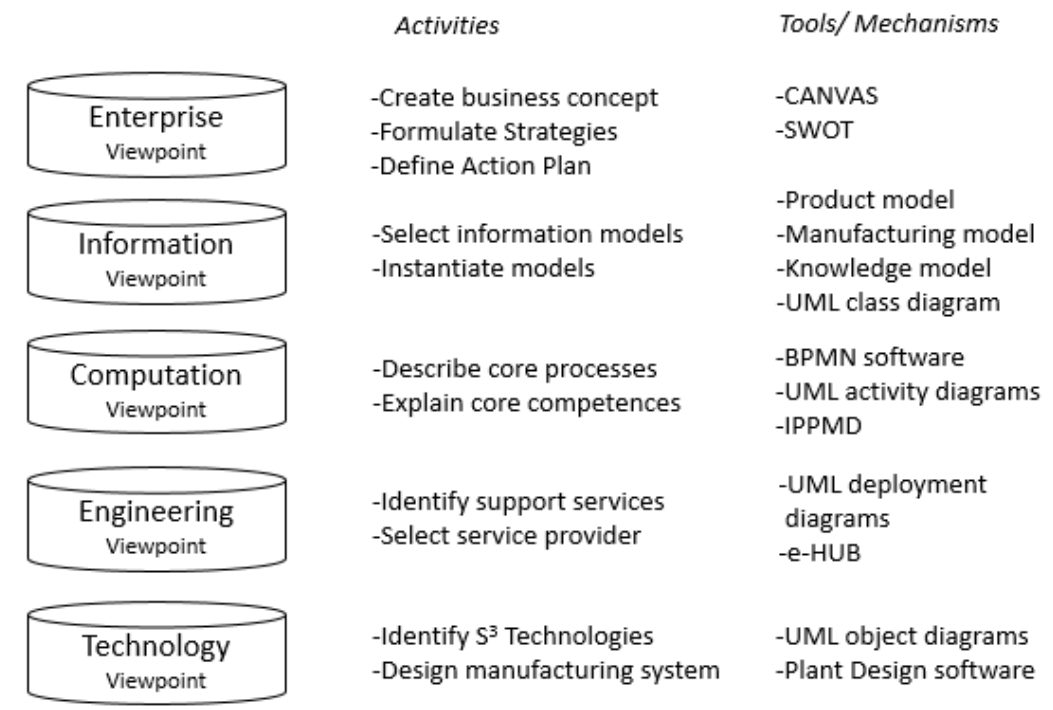

Fig. 2. Activities to be done on each viewpoint and tools that can be used.

\subsection{Action-Research}

Action-research is a family of methodologies that pursue a change and an understanding. The use of spiral processes or cycles alternating between action and reflection provides a refinement of methods [12]. In action-research the investigators test theories and then adjust them according to feedback [13]. Each cycle consists of four phases:

- Plan.- This phase establishes the action plan and must be originated from a future perspective considering risks.

- Act.- In this phase the action is taken based of the previous plan.

- Observe.- In this phase all the events that are happening need to be documented and a projection of a future is created.

- Reflect.- This phase is the result of the observation and it helps to construct a new plan if needed.

In 2012 the methodology was used by Nogueira et al [6] to implement the Zachman Framework. They showed that action-research aids with the implementation of frameworks by SMEs. 


\section{Sensing, Smart and Sustainable Enterprise - Methodology}

The proposed methodology in this paper has two structure levels. The external level includes the viewpoints defined in the $S^{3} E-R M$, and the internal level has the four phases of action-research.

The external structure is a sequence of action-research cycles, in which each cycle represents a viewpoint of the enterprise model. As seen in Fig. 3, the cycles start with the instantiation of the Enterprise viewpoint, and end with the instantiation of the Technology Viewpoint. The viewpoints can be modeled with UML diagrams [10] or other tools. When the five cycles end, the enterprise model is constructed.

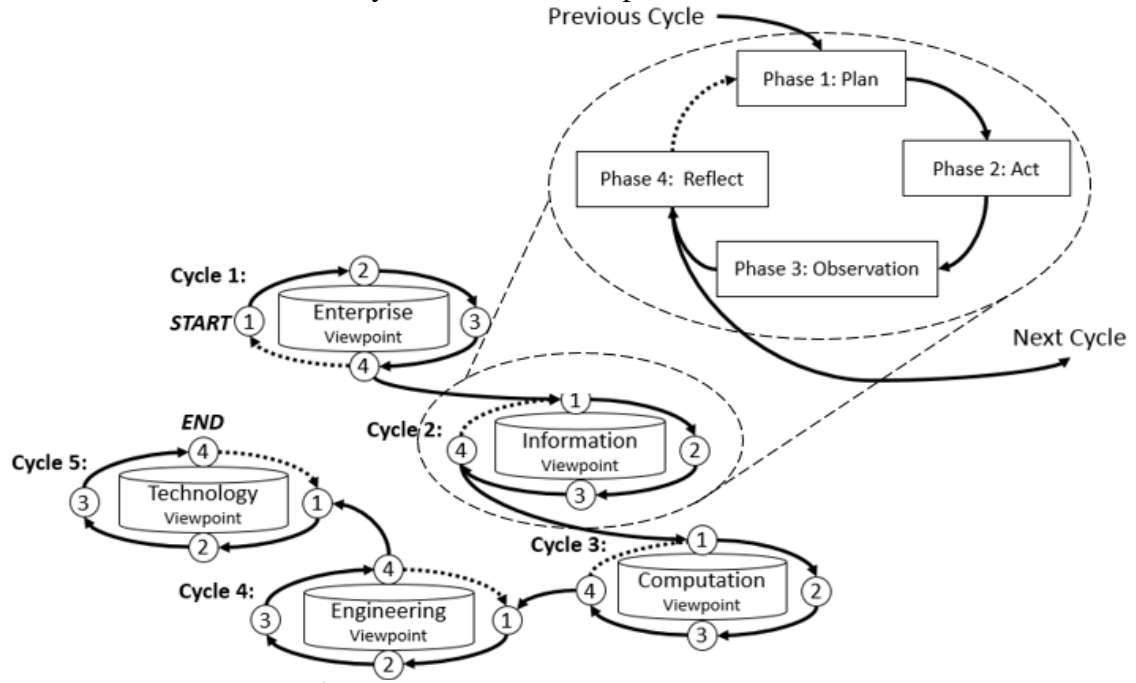

Fig. 3. Structure of the $S^{3} E-M e t h o d o l o g y$. Five cycles for defining five viewpoints and four phases inside each cycle.

As seen in Fig. 3, the internal structure of each cycle consists of the action-research phases i.e. Plan, Act, Observe and Reflect. For this research, the first phase consists of defining:

- the objectives of the cycle, which include the Sensing, Smart and Sustainability $\left(\mathrm{S}^{3}\right)$ concepts,

- the information needed for this cycle,

- the series of steps to accomplish the objectives (activities shown in Fig. 2),

- the performers for the corresponding cycle,

- the tools for accomplishing the objectives (Fig. 2).

The second phase consists of the execution of the activities defined in the first phase. For some cycles, the set of activities include the development of other methodologies.

The third phase is an evaluation of the activities done during the second phase. The evaluation not only contemplates the consistency of information, but also the inclusion of elements for the adoption of the Sensing, Smart and Sustainable concepts. 
In the fourth phase, the necessary adjustments are based on the results of the evaluation. Then, a decision is made to a decision is made, stay at phase one of the same cycle or continue to the next cycle.

To guarantee the adoption of the Sensing, Smart and Sustainable concepts, special considerations must be taken into account when instantiating each viewpoint. At the enterprise viewpoint, sensing entails the existence of megatrends implications in the business concept. The smart concept is realized by explaining how the business model canvas elements (building blocks) [14] provide reaction capabilities to cope with changes in the business environment. In addition, sustainability is realized by adding performance indicators that address social, environmental, and economical issues. At the information viewpoint, the sensing concept is realized by defining information models that support the information requirements identified at the enterprise viewpoint. The smart concept is realized by developing information models for representing product models and manufacturing models. Moreover, sustainability is realized by developing information models that support evaluation of environmental impact. At computation viewpoint, the sensing concept refers to processes for acquisition of information, for example, contact between the enterprise and the customer. The smart concept is realized in the structure of the processes; the processes should be defined to adapt to changes. To realize the sensing concept at engineering viewpoint, identification of possible partners is done. The smart concept is realized by recognizing the services needed to apply the process. In addition, social sustainability is realized by ensuring that the collaboration affect all members equally and fairly Finally, at technology viewpoint the smart, sensing, and sustainable resources are identified.

The methodology can be used to create the partial or particular models. When the purpose is to create partial models, the users are creating structures that define more than one enterprise. The enterprises described share similar characteristics. And when the purpose is to create a particular model, the model describes a specific enterprise. Both applications are shown in the following sections.

\section{Partial Model: Collaborative Networks for Mass Customization}

As stated before, an instantiation of the $\mathrm{S}^{3} \mathrm{E}-\mathrm{RM}$ will be needed to fulfill two purposes: to develop a customized product, and to define a Collaborative Networked Organization. Mehrsai et al [15] explains that isolated enterprises fall short in facing challenges of mass customization. Therefore, companies prefer to collaborate with others in order to achieve global reach and local responsiveness in the context of mass customization. In this paper, we explore the design of collaborative networks to manufacture mass-customized products. The key features of mass customization are identified in [1]: unpredictable demand pattern, heterogeneous niches, low-cost, highquality, customized goods and services, short product development cycles, and short product life cycles. For Collaborative Networked Organization the main characteristics are explained by Camarinha-Matos et al [16]: autonomous, distributed, heterogeneous entities, collaboration to achieve compatible goals and generate value; and interactions supported by computer networks. The results when using five cycles for creating the partial model, considering the above-mentioned characteristics, are presented next. 
Cycle 1 - Enterprise Viewpoint

For this cycle, the objective is to create the business concept, define the strategies and select the core process and competences. The actors for this activity are identified, mainly marketing experts are needed. The tool for the realization of this viewpoint is the business model canvas (CANVAS).

- CANVAS concepts identified for the partial level:

- Value proposition- mass customized product

- Customer segments- all customer that wants a customized product

- Strategies:

- Competitive strategy- mass customization - low cost

- Value Chain strategy- Collaboration (Collaborative Networked Organization)

- Production strategy- Build to Order, Make to Order, Configure to Order

- Core Process: product realization (customization), order fulfilment.

- Core competences: negotiation (Collaborative Networked Organizations), manufacturing of personalized products.

Because collaboration is pursued, an evaluation regarding open business models must be done. The Benson typology [17] can be used for such evaluation. Benson states eight types of business model, where the type I business model have complete internalization of the value system. As the type number increases, the externalization grows. Therefore, the type VIII is an externalized business model where the firm may not have any assets and the value generation depends on negotiation skills. The highest type is better for Collaborative Networked Organizations.

\section{Cycle 2 - Information Viewpoint}

The objective for this cycle is to define the Product Model, Manufacturing Model and Knowledge Model. The information needed is produced during the design of a customized product. The performers for this cycle are design and manufacturing engineers. The designing process can be supported with CAX (i.e. CAD, CAM, CAE) and PLM tools.

Two information models are selected. The product model proposed in [10] has function, solution and physical model. Usually the costs, dimensions and materials are described at the physical model. For allowing customization, those characteristics are included also in the solution model. Therefore, the function, and solution models act as restrictions to the customization at the physical model. The manufacturing model selected [10] has process, resources and strategies of the facilities, allowing a rapid configuration of process and resources for new and customized products. For the evaluation of this cycle, a prototype created from the physical model is presented. In addition, CAM software, can be useful to visualize the manufacturing process and evaluate the information models.

Cycle 3 - Computation Viewpoint

This viewpoint is for defining the core business processes. The performers for this phase are the industrial engineers and people that understand the nature of each process (e.g. marketing experts for obtaining customer commitment process). The modelling of 
the business process is done with ARIS modelling language because it incorporates different views (e.g. Organizational, Data, Control, Functional).

When product life cycles are short, product realization must be fast. This can be designed with the Integrated Product, Process, and Manufacturing systems Development reference framework [18]. The order fulfillment process must be done with the union of competences of enterprises, so negotiation activities must be considered to enhance co-design (with customer), co-engineering, and collaborative manufacturing.

\section{Cycle 4 - Engineering Viewpoint}

The objective of this viewpoint is to define where the Business Processes are going to be implemented. The list of possible partners with their competences and resources is the information needed. The performers are people with expertise in the specific eservices [10].

Two e-services are identified for the partial model. E-brokerage is needed to provide negotiation skills, and e-supply is used to add reaction capacity to changes in demand. The e-applications must include customer and supplier relationship management systems. Finally, CAD technologies must be included to provide personalization.

Because this viewpoint considers the distribution of the services, it must be evaluated as a network. The network characteristics proposed by Frankenberg et al [19] can be used (See Fig. 4). For the partial model, customer centricity is high due to the mass customization strategy, so the configuration for high customer centricity is pursued.

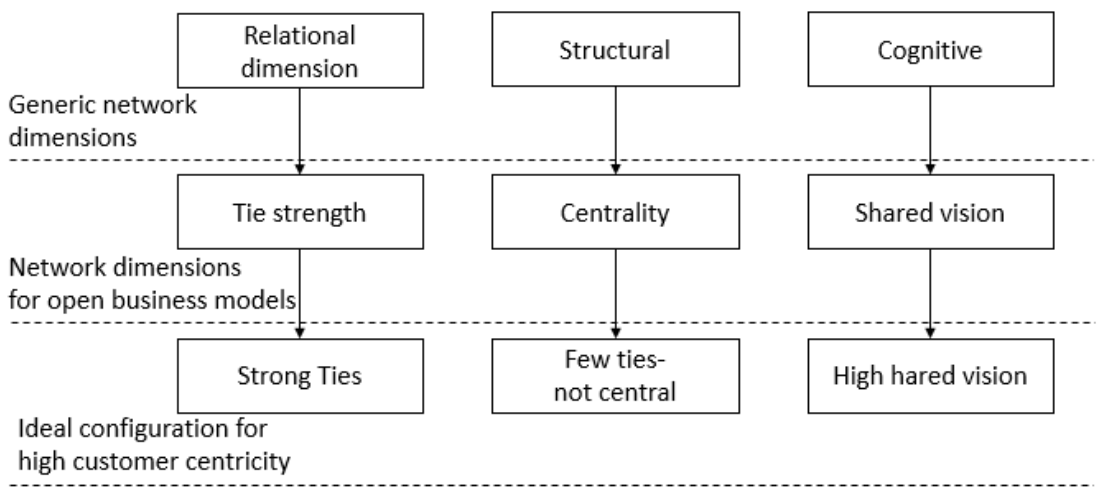

Fig. 4. Ideal network configuration for customer centric open business models.

\section{Cycle 5 - Technology Viewpoint}

Considering all the information described above, the manufacturing system is designed. Using the manufacturing model a network must provide the different activities form production to sales. To create the manufacturing network, first an identification of resources is needed. Technologies that support sensing are the ones that allow communication (collaboration) PLC, WSN, SaaS, CRM, SRM. The smart resources provide knowledge based execution of activities CNC, PLC, ERP. The efficient use of previous mentioned resources push sustainability. 


\section{Particular Model: Promotional Articles}

The case study is an enterprise of promotional articles for Tecnologico de Monterrey. The mission of the enterprise is connect the final users with the product; this connection is possible by the belonging feeling with the Tecnologico de Monterrey symbols. Using the methodology a manufacturing system for promotional articles was developed. Two undergraduate students (Jessica Velázquez and Rebeca Cisneros) developed an example of promotional article in 2015. It is an iPhone cover case engraved with the Tec Logo and the user's nickname. They chose the iPhone 5 cover because it is the most used at Tecnologico de Monterrey. The outcomes are presented.

\section{Cycle 1 - Enterprise Viewpoint}

CANVAS:

- Value Proposition.- Mass customized product

- Customer Relationship.- Emotional and useful products

- Customer Channels.- on-line sales, Tec-Stores

- Customer Segments.- Alumni and workers at Tecnologico de Monterrey.

- Key Activities.- designing, manufacturing, marketing

- Key Resources.- Tec-stores, Milling Machines, CAD applications

- Key Partners.- Tecnologico de Monterrey (Tec stores), engraving and 3D printer Enterprises.

Strategies:

- Competitive strategy.- Mass customization \& Low cost

- Value Chain Strategy.- Vertical Collaboration (Collaborative Network Organization)

- Production Strategy.- Built To Order

Core process: Order Fulfillment

Core competences: Negotiation and Manufacturing capabilities (Engraving, 3Dprinting)

\section{Cycle 2 - Information Viewpoint}

Product Model: Figure 5 shows the product presentation using CAD Software. It is an acrylic cover case, with logo engraved in aluminum.

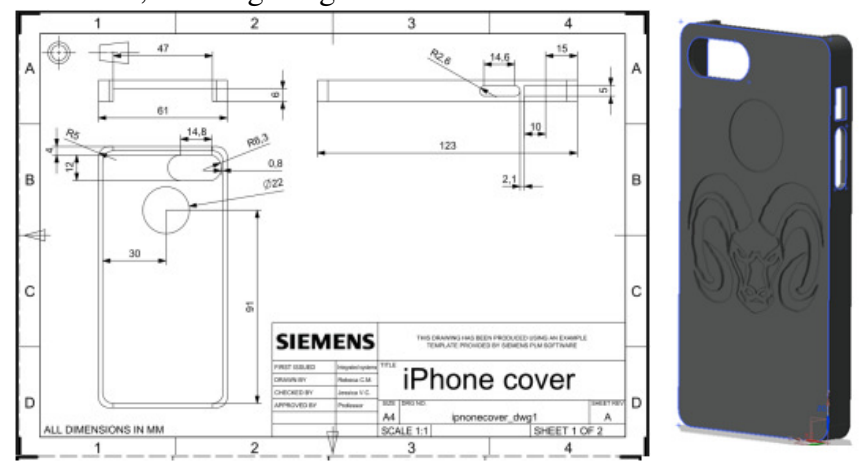

Fig. 5. Cover case presented in $\mathrm{CAD}$ tools. 
Manufacturing Model:

- Process: Engraving, 3D-printing

- Resources: Reconfigurable Micro-Machine, 3D-printer

- Materials: Aluminum, plastics

Cycle 3 - Computation Viewpoint

The diagram for the core process was modeled with the ARIS modelling language. A detailed level of representation using, resources, organization and process representation was needed to correctly understand and evaluate the order fulfillment process. A representation of the core process is appreciated in figure 6 . The process starts when the final users fill a template, which includes the information about the order. This process is done in Tec-Stores. Once the personalized order has been generated they pay the order. The order is sent to two companies, the company that manufactures plastics (Enterprise A) and to the one that engraves them (Enterprise B). While the manufacture is completed, enterprise B designs the personalization using $\mathrm{CAD}$. After, when they receive the cover-cases they engrave them with the micromachine [18] according to the design. Finally, the company ships the order to the Tecstores where the final user can take up his personalized cover-case.

\section{Cycle 4 - Engineering Viewpoint}

In the engineering viewpoint, first the network was designed and then evaluated using the Frankenberg configurations. As seen in figure 6, the network has few and strong ties, and the enterprise share their vision that is to deliver the personalized product. The e-services to maintain the network configuration is e-brokerage. This service was offered with negotiation platforms (SRM and CRM). The e-Applications used for the core process are the following: PLM-CAD for design of the customization and ERPs for the planning. The interactions are done with and trough the e-HUB.

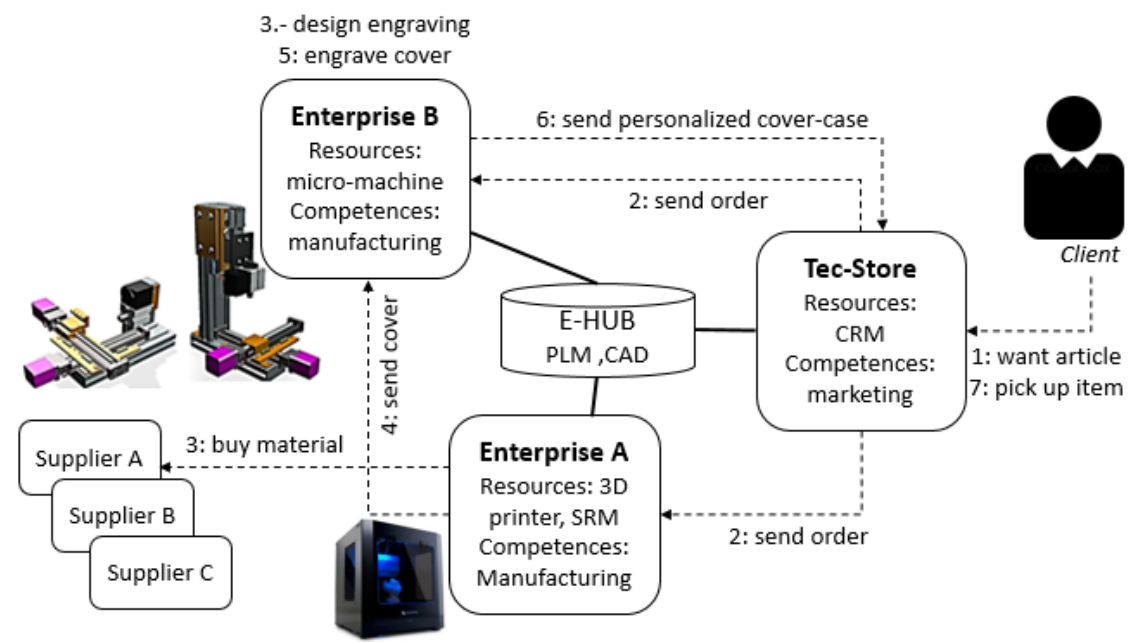

Fig. 6. Collaborative Networked Organization for customized promotional articles, and order fulfillment process. 
Cycle 5 - Technology Viewpoint

Finally, in the technology viewpoint manufacturing system is designed. As seen in figure 5, the collaborative network considers two micro-machines [18] and a 3Dprinter. The smart resources are: CNCs for controlling the machines, the Customer Relationship Management system and the Supplier Relationship Management System and the relationship management systems. The sensing resources are WSN and Realtime systems, the interactions are supported with an e-HUB.

\section{Discussion and Conclusion}

A reference model to design and create sustainable, smart and sensing enterprises has been instantiated in order to define a partial model for a specific type of firm that could produce mass-customized products using a Collaborative Networked Organization as its integrated manufacturing system. In addition, a case study to create an instantiation of such partial model has been developed to demonstrate its usage in a real product and collaborative manufacturing system.

A methodology based on action-research has been used to support in a systematic manner the instantiation process. The methodology was easily adaptable to a specific case, and as a result, the five viewpoints were instantiated to satisfy the requirements of mass-customized products and use of a $\mathrm{CNO}$ for production. The action-research phases allowed the evaluation and learnings while applying the methodology.

When the methodology was used for partial modeling, only some specific outputs can be stated, especially in the enterprise viewpoint. However the definition of reference tools (methods) were selected (Benson typology and Frankenberg configurations for evaluation, and Canvas, IPPMD, ARIS for activities realization) in order to guide a designer to a more practical and faster instantiation.

Therefore the methodology for particular instantiation is easy of use, pragmatic and straightforward because constrains are already defined, and tools has been selected. A Collaborative Network for Manufacturing was configured with the right processes and competencies to ensure quality, speed and delivery of the mass-customized product. The use of multiple core competences allowed the flexibility needed to achieve a Build To Order production system based on a collaborative network.

It is important to point out that the standardization in each viewpoint is different. In the case of the enterprise and computation viewpoint, due to the fact that models are available (e.g. Canvas, IPPMD, ARIS Core Process Models), the instantiation is more straightforward and structured. In the information viewpoint the existence of predefined information models (Product \& Manufacturing) permits its correct instantiation. The Engineering viewpoint with an e-HUB of services, applications and technologies allows the configuration of an information system platform with will support the CNO execution. However, the networks implications must be further studied to have standards models and methods that aid CNO configurations in an automatic way. Moreover, sustainability was issued during the product development process, but it was not clear how to include it in all the core processes. 


\section{References}

1. Tseng, M. M., Hu, S. J.: Mass customization: In: Cirp Encyclopedia of Production Engineering (pp. 836-843). Springer Berlin Heidelberg. (2014)

2. Jorysz, H. R., Verndat, F. B.: CIM-OSA Part 1: total enterprise modelling and function view. International Journal of Computer Integrated Manufacturing, Vol. 3, 3-4,144--156, (1990)

3. Berio, G., Vernadat, F.: Enterprise modelling with CIMOSA: functional and organizational aspects. Production planning \& control, 12(2), 128-136. (2001)

4. Hanneghan, M., Merabti, M., Colquhoun,G.: A viewpoint analysis reference model for Concurrent Engineering, Computers in Industry, Volume 41, Issue 1, 35--49, ISSN 01663615, http://dx.doi.org/10.1016/S0166-3615(99)00038-X. ,(2000)

5. Monfared, R. P., West, A. A., Harrison, R., Weston, R. H. An implementation of the business process modelling approach in the automotive industry. Proceedings of the Institution of Mechanical Engineers, Part B: J of Engineering Manufacture, 216(11), 1413--1427, (2002)

6. Nogueira, J. M., Romero, D., Espadas, J., \& Molina, A.: Leveraging the Zachman framework implementation using action-research methodology-a case study: aligning the enterprise architecture and the business goals. Enterprise Information Systems, 7(1), 100-132. (2013)

7. Zwegers, A., Tolle, M., Vesterager, J.: VERAM: virtual enterprise reference architecture and methodology. In VTT symposium (Vol. 224, pp. 17-38). VTT; (2003)

8. Bernus, P., Noran, O., Riedlinger, J.: Using the globemen reference model for virtual enterprise design in after sales service. In VTT SYMPOSIUM (Vol. 224, pp. 71-90). VTT; (2003)

9. Weichhart, G., Molina, A., Chen, D., Whitman, L. E., Vernadat, F.: Challenges and current developments for Sensing, Smart and Sustainable Enterprise Systems, Computers in Industry, ISSN 0166-3615, http://dx.doi.org/10.1016/j.compind.2015.07.002. (2015)

10.Chavarría-Barrientos, D., Espinosa, J. M. M., Batres, R., Ramírez-Cadena, M., Molina, A.: Reference Model for Smart x Sensing Manufacturing Collaborative Networks-Formalization Using Unified Modeling Language. In Risks and Resilience of Collaborative Networks (pp. 243-254). Springer International Publishing.(2015)

11.ISO ISO/IEC 10743-3. Information Technology - Open Distributed Processing - Reference Model: Architecture, International Standards Organization, Geneva, Switzerland, (2009)

12.Baskerville, R. L., Wood-Harper, A. T.: A critical perspective on action research as a method for information systems research. Journal of information Technology, 11(3), 235-246. (1996)

13.Avison, D., Baskerville, R., Myers, M.: Controlling action research projects. Information technology \& people, 14(1), 28-45. (2001)

14.Osterwalder, A., Pigneur, Y., Tucci, C. L.: Clarifying business models: Origins, present, and future of the concept. Communications of the association for Information Systems, 16 (2005)

15.Mehrsai, A., Karimi, H. R., Thoben, K. D.: Integration of supply networks for customization with modularity in cloud and make-to-upgrade strategy. Systems Science \& Control Engineering: An Open Access Journal, 1(1), 28-42. (2013)

16.Camarinha-Matos, L. M., Afsarmanesh, H., Galeano, N., Molina, A.: Collaborative networked organizations-Concepts and practice in manufacturing enterprises. Computers \& Industrial Engineering, 57(1), 46-60. (2009)

17.Benson-Rea, M., Brodie, R. J., Sima, H.: The plurality of co-existing business models: Investigating the complexity of value drivers. Industrial Marketing Management, 42(5), 717729. (2013)

18.Pérez, R., Molina, A., Ramírez-Cadena, M. Development of an integrated approach to the design of reconfigurable micro/mesoscale CNC machine tools. Journal of Manufacturing Science and Engineering, 136(3), 031003.3. (2014)

19.Frankenberger, K., Weiblen, T., Gassmann, O.: Network configuration, customer centricity, and performance of open business models: A solution provider perspective. Industrial Marketing Management, 42(5), 671-682.2 (2013) 